\title{
O DEMOGEOGRAFSKOM PROCESU U (NE)URBANOM PROSTORU SR HRVATSKE
}

\author{
Mladen Friganovic*
}

IZVLEČEK

UDK 911.3:312 (497.13)

Članek obravnava demogeografska gibanja ter $s$ tem povezano urbanizacijo Hrvatske in opredeljuje tipe demogeografskih procesov.

ABSTRACT

UDC $911.3: 312(497.13)$

ABOUT DEMOGRAPHIC PROCESS IN (NON)-URBAN AREAS OF THE SOCIALIST REPUBLIC OF CROATIA.

The article presents demographic changes and their interactions with urbanization in the SR Croatia according to the type of demogeographic type.

\section{UVOD}

Posljednjih godina Geografski odjel Prirodoslovno-matematixkog fakulteta Sveuxilišta u Zagrebu usmjerio je svoje znanstveno istraživanje na studij regija (V.Rogić), tipologiju opcina (I. Crkvenčic) i urbanizaciju SR Hrvatske (M.Friganovic)). Rezultat tog istraživanja (navedeni su koordinatori potprojekata) mogao bi se sintetizirati pod naslovom "Gcografski aspekt osobina, procesa i problema SR Hrvatskc".

Kao voditelj jednog od potprojekata (Geografski aspekt urbanizacije SR Hrvatske( iznijet cu dio rezultata istraživanja međuregionalne, urbanogeografske i populacijskogeografske razlǐnosti i difcrencijalne problematike.

\section{STUPANJ I OSNOVNO OBILJEŽJE URBANIZACIJE}

U analizi se pošlo od razvijenosti regionalnih struktura i prostorno diferencijalnih socio-gospodarskih procesa promatranih kroz dinamiku i strukturu stanovništva. Jer, stanovništvo (i naseljenost) su refleks prostorno razlixnog trenda $s$ implikacijama dugoročnog djelovanja. Suvremeni proces otkriva sve vecu podvojenost prostora SR Hrvatske. Istič se manjeobuhvatna područ ja koja demografski i naseobinski jačaju i područja koja slabe. Njihove se površine odnose kao 1:3, a stanovništvo kao 1:1

\footnotetext{
- Dr,,univ.prof., Geografski odjel PMF, 41000 Zagreb, Maruličev trg 19, YU.
} 
(Friganovic, 1980-1981). Ovakav omjer površine i stanovništva dvaju podrux ja s razlicitim trendom i općim društveno-gospodarskim obilježjem nalaže sustavno istraživanje kao fundamentalnog zadatka u buducoj organizaciji prostora SR Hrvatske. Jer, razlicna ce pulsacija u urbanom i ostalom prostoru ploditi jos jacom a neželjenom i neracionalnom diskrepancom. Urbane jezgre pojedinih regija vec sada pokazuju razlixnu ulogu u prostoru, nejednaku tipologiju i razliciti stupanj ruralno-urbane polariziranosti (Vresk, 1982-1983).

S urbanizacijom su narasli mnogi problemi, pa i problem urbane mikroklime i življenja u njoj. Iz odnosa grada i njegove (mikro)klime utvrdene su mnoge cinjenice (Šegota, 1987). Dosadašnji rezultat ukazuje na potrebu postojanog pracenja i korelativnog objašnjavanja prostorno-vremenske varijabilnosti najznaðajnijih urbano-klimatskih parametara.

Ostvarenjem spomenutih zadataka pružila bi se mogucnost njihove primjene u prostornom planiranju, posebno u regionalnom planiranju i u postizanju zdravljeg odnosa urbanog i ostalog životnog prostora. No, u metodoloskom pogledu još nije dosegnuta zadovoljavajuća razina istraživanja. Tome je više uzroka koji se protežu u Sirokoj lepezi od subjektivnih do objektivnih. Oslabljena materijalna osnovica znanstvenih istraživanja sputava mlade istraživač da se opreme novim pomagalima i vežu na banku podataka o (ne)urbanom prostoru. A bez toga ce biti veoma tesko unaprijediti metodologiju demogeografske, urbanogeografske i prometnogeografske problematike. Neka preliminarna istraživanja pokazala su i nekoherentnost prometne mreže te nezadovoljavajucu koordiniranost prometa SR Hrvatske (Sic, 1984). Pri tome valja istaci i nepovoljnost samog oblika SR Hrvatske za homogenije i suvremenije prostorno povezivanje.

\section{IZ REZULTATA ISTRAZ̆IVANJA}

Jedan od temeljnih pokazatelja prostorne redistribucije stanovniStva (i naseljenosti), kao refleksa opcih društveno-gospodarskih promjena, jest populacijska dinamika u (ne)urbanim naseljima i prostoru. To je svojevrstan podatak o opcem prostorno diferencijalnom življenju, odgovarajucem procesu i problemima. Oxituje se prenaglasenost ruralno-urbane dihotomije. Njihova polariziranost postaje iz dana u dan veca i tegobe prostorne organizacije brojnije. Takva je polariziranost zapoðela davno, ali se razmahala sedamdesetih godina i danas se osjeća u svim aspektima prostorne organizacije u SR Hrvatskoj. 
Stanovništvo opcinskih središta (svi gradovi i nešto mjeک̌ovitih naselja) povecalo je svoj udio u stanovnistvu SR Hrvatske u razdoblju 1948-1981. od $25 \%$ do $47 \%$. Prema tome, udio ostalih (ruralnih) naselja smanjen je od $75 \%$ do $53 \%$. Taj se trend u medupopisnim razdobljima vidi iz ove tablice (Friganovic M., 1980-1981):

$\begin{array}{lccccc} & 1948 & 1953 & 1961 & 1971 & 1981 \\ \text { SR Hrvatska } & 100 & 100 & 100 & 100 & 100 \\ \text { Opcinska sredista } & 24,9 & 27,1 & 32,1 & 40,0 & 46,6 \\ \text { Ostala naselja } & 75,1 & 72,9 & 67,9 & 60,0 & 53,4\end{array}$

Intenzitet promjene u međupopisnim razdobljima otkriva vremensku modificiranost i prostorno diferencijalnu pulsaciju. To se vidi iz ove tablice o prosjeとnim godišnjim vrijednostima u promilima:

\begin{tabular}{|c|c|c|c|c|c|}
\hline & $1948-1953$ & $1953-1961$ & $1961-1971$ & $1971-1981$ & $1948-1981$ \\
\hline $\begin{array}{l}\text { Opcinska } \\
\text { srcdišta }\end{array}$ & 4,4 & 6,3 & 7,9 & & \\
\hline $\begin{array}{l}\text { Ostala } \\
\text { nasclja }\end{array}$ & $-4,4$ & $-6,3$ & $-7,9$ & $-6,6$ & $-6,6$ \\
\hline
\end{tabular}

Regionalne su razlike vrlo izrazite. (Ne)urbaniziranost otkriva naseobinske slabosti pojedinih podrucja SR Hrvatske. Prostori minimalne urbaniziranosti na razini zajednicc opcina jesu Lika (ZO Gospić) sa samo $22,3 \%$ urbanog stanovništva (1981), siri prsten Zagrcba $(18,8 \%)$, ZO Varaždin $(20,9 \%)$ i dr. Na drugoj so strani ljestvice ZO Grada Zagreba $(92,9 \%)$ i ZO Rijeke $(55,1 \%)$.

Urbanizacija se u grubom aspektu prati i kroz prostornu redistribuciju stanovništva, kroz razvoj onjera imigracijskih i emigracijskih područja te njihova stanovništva, kroz razvoj omjera podruxja s pozitivnom i negativnom migracijskom bilancom. U razdoblju 1971-1981 populacijska se koncentracija s naglasenim rastom urbanog stanovnistva odvijala u $27 \%$ općina SR Hrvatske (zahvaćaju $24 \%$ teritorija) s $47 \%$ stanovništva SRH, dok je egzodusno obilježje (negativna migracijska bilanca) imalo $73 \%$ opcina ( $76 \%$ teritorija SRH) sa samo $53 \%$ stanovnistva republike. Od ukupno 10 zajednica opcina (makroregije) SR Hrvatske, osam ih ima negativnu migracijsku bilancu (sve osim ZO grada Zagreba i Rijeke). Ali i unutar samih egzodusnih opcina odvija se populacijsko-naseobinska polarizacija koja na svojevrstan nađin pokazuje snagu urbanizacije i deruralizacije. U razdoblju 1971-1981 stanovnistvo se gradskih naselja povećalo cak $16 \%$ (lepeza promjene u ZO je od $10 \%$ u ZO Gospic do $38 \%$ u ZO Zagreb okolica). Istovremeno stanovništvo ostalih (ruralnih) naselja smanjilo se $6 \%$ (od $5 \%$ u ZO Rijeke do $23 \%$ u ZO Gospica).

Ono sto je posebno karakteristiðno jest, da se relativno naglašena ruralno-urbana polarizacija naseljenosti odvija u podrucjima koja su dobrim dijelom u odmaklom 
stupnju egzodusa, (kakva je ZO Gospic i kakva je ZO Karlovac) ili su potpuno u odmaklom tipu egzodusa (kakva je ZO Bjelovar). Recentna istraživanja potvrđuju daljnje produbljivanje tog procesa (Friganovic, 1982-1983).

Nasuprot nekocnjem obilježju stanovništvo gradskih naselja ima danas znatno veču stopu radanja i prirodnog prirastaja $(8,2 \%$.) nego ruralna naselja $(1,7 \%$. godišnje u 1971-1981). No, u prosjeku je stopa rađanja stanovništva SR Hrvatske iz godine u godinu niža i sama po sebi predstavlja problem u reprodukciji. Sve je niža stopa nataliteta, a sve viša stopa mortaliteta. Prva karakteristika iskače iz teorije demografske tranzicije, a druga je funkcija starenja populacije SR Hrvatske. Disproporcija dobnog sastava stanovnistva sela i grada posljedica je ruralnog egzodusa u protekla cetiri i nešto viš desetljeća. Sudeći prema današnjem stanju i procesu diferencijalni natalitet gradskih i seoskih naselja bit ce osnovno obilježje prirodnoga kretanja stanovnistva SR Hrvatske i u neposrednoj buducnosti. Zbog nedovoljne biološke obnove i starenja populacije nastavit ce se trend porasta mortaliteta, osobito u seoskim prostorima. Ocjena kretanja determinanata prirodnoga kretanja stanovnistva vodi nas k zakljucku da ce stanovniß̌tvo SR Hrvatske potkraj stoljeća imati višu stopu umiranja nego rađanja (Nejasmic, 1986). Današnje prostorno planiranje moralo bi uzeti taj parametar kao jedan od osnovnih. Ali, ono to, nažalost, ne cini. Zašto, ne znamo. Ali, što ce se dogoditi, po prilici znamo. To je zato,jer je veći utjecaj politickog pragmatizma nego li znanosti u životu naŠg drustva i njegove prostorne organizacije. A nije daleko dan kada ce se u selu SR Hrvatske na stotinu umrlih roditi samo 44 djeteta (Nejašmić, 1986, 35). Selo SR Hrvatske je već početkom druge polovine sedamdesetih godina poprimilo karakteristike negativnog prirodnoga kretanja (manje rodenih nego umriih) s elementima ubrzana trenda. To se vidi iz ove tablice (Nejasmic, 1986):

Prosječna godišnja stopa prirodnog priraštajana 1.000 stanovnika

Godina

SR Hrvatska Gradska Mjesovita Seoska

$\begin{array}{lrrrr}1984 & 2,3 & 6,5 & 2,5 & -3,6 \\ 1991 & 1,5 & 5,7 & 1,0 & -6,3 \\ 1995 & 0,8 & 5,1 & -0,2 & -8,3 \\ 2000 & -1,3 & 4,2 & -2,0 & -1,2\end{array}$

Potkraj stoljeça ce prirodna dinamika stanovnistva SR Hrvatske biti na pragu posvemašnje depopulacije, dok ce jaz između prirodnoga krctanja stanovništva gradskih i seoskih naselja biti veoma dubok. A tko se od takvog trenda danas zamislio? To ne znam, ali znadem da se ništa ne poduzima da bi se trend korigirao i umanjila šteta nadolazećih posljedica. Žalostno je kada upravljač razmišljaju aritmeticki a proces se odvija geometrijskim redom.

Urbanizacija SR Hrvatske analizirana je i uz pomoc nekih drugih indikatora (velixina 
naselja, broj djelatnog (ne)poljoprivrednog stanovnistva, velicina domacinstava bez zemlje i dr.). Po takvoj shemi izdvojeno je u SR Hrvatskoj stotinu naselja gradskog tipa (47,8 \% stan. SRH 1981). Pokazala se prilixna neregularnost i nesklad reda velixine urbanih naselja izmedu republickog centra, makroregionalnih sredista i centara nižeg reda do općinske mikroregije. Izraz je to opce nerazvijenosti,prirodnogeografske osnove i povijesno-geografske posebnosti pojedinih podruxja republike u uvjetima nekontrolirana i virulentna poslijeratna egzodusa sa sela. Znatne su i znaðajne razlike u urbanizaciji nekih regija i urbanih prstenova njihovih sredista (Vresk, 1982-1983). Te razlike ukazuju na regionalne razlike socio-ekonomskog dinamizma. One izazivlju rasprave $\mathrm{i}$ traže poseban pristup njihovu proucavanju $\mathrm{i}$ interpretaciji. One traže i poseban pristup populacijskoj politici koja u SR Hrvatskoj dosada nije uopce postojala (Friganovic, 1984).

Jedan od temeljnih problema jest kako zaustaviti daljnju depopulaciju i sprijeciti izumiranje seoskih naselja u mnogim podruxjima SR Hrvatske. Kako sprijeciti njihovo društveno-gospodarsko propadanje? Kako modificirati migraciju koja bi trebala revitalizirati pojedine ruralne predjele? Kako uxiniti življenje na isturenim i malim otocima Jadrana, te u brdsko-planinskim predjelima dinarskoga gorja prihvatljivim u suvremenom društvu? Na sva ta pitanja znanost, a i društvo traže odgovor. Za sada pouzdano znamo da postoji veoma visoka korelacija društveno-gospodarske nerazvijenosti i stupnja depopulacije u svim regijama SR Hrvatske (Friganovic, 1984).

Demografsko slabijenje (dinamicko i strukturno) vanurbanih prostora SR Hrvatske ox̌ituje se još drastienije u đobno-spolnoj strukturi stanovništva (Friganović, 1985). U inace ostarjelom dobnom sastavu stanovništva SR Hrvatske (1981. god.: 28,2 \% starih od 0-19 godina, a $14,9 \%$ starijih od 59 godina) siri se jaz izmedu dobnog sastava stanovništva seoskih i gradskih naselja (1981: koeficijent starosti stanovništva gradskih naselja bio je 0,46 a ostalih naselja 0,65 ). Prema tome, ne radi se samo o posustaloj dinamici broja stanovništva ruralnih podrucja, već i o znatno okrnjenoj dobnoj strukturi, odnosno o dinamicko-strukturnoj dihotomiji naseljenosti SR Hrvatske. Signifikantne razlike su i u koeficijentu maskuliniteta, ali, na srecu, samo kod starijih generacija (ostaci diferencijalnog mortaliteta ratnih kohorta). Sve to upucuje na posljedice sto se javljaju u općoj naseobinskoj distribuciji i u životu SR Hrvatske uopce.

Analiza 124 sredista rada u SR Hrvatskoj 1981. godine pokazala je nepravilan razmjestaj tih centara obzirom na njihovu velixinu i polariziranost radnih mjesta (superkoncentracija i deficitarnost radnih mjesta). U Zagrebu je radilo $28,4 \%$ svih zaposlenih u republici. U sva Cetiri makroregionalna sredista (Osijek, Rijeka, Split i Zagreb) radilo je $47 \%$ zaposlenin u SRH. Medutim, pokazaio se i to da svaka opcina ima svoj pol koncentracije rada i gravitacijskog toka zaposlenosti (Vresk, 1986). Koncentracija radnih mjesta, koja je uvjetovana uglavnom industrijskim razvojem, jest u 
gradovima. Ti gradovi (opcinski centri) razvijaju daljnje polarizacijske efekte što se oxituje u koncentraciji stanovništva i stanovanja te ostalih odrednica urbanog življenja. Negativni efekt takve koncentracije vidjeli smo u depopulaciji i ostarjelosti stanovnistva ruralnih prostora sto se sve skupa pretvara u potencijalno razornog ¿inioca. Relativno pozitivne efekte ima dnevna migracija koja oživljuje siru okolicu većih ccntara rada (urbanizacija rurisa). Ta gravitacijska podruxja dnevne migracije imaju regionalno diferencijalna obilježja obzirom na snagu i brzinu urbanizacije ruralnog prostora. Međutim, zapaženo je da su pretežno unutar opcinskog teritorija, tj. poklapaju se s opcinskim međama (Vresk, 1986).

Polarizacijski efckti urbanizacije Dalmacije, Like, Istre, središnje Hrvatske i Slavonije pokazuju odgovarajuce modifikacije (Vresk, 1987). Pri tome je metropolitanska regija Zagreba vrlo istaknuti specifikum (Vresk, 1984).

Analiza geografski relevantnih obilježja metropolitanske regije Zagreba pokazala je, da nju cine 137 naselja s ukupno 841 tisucom stanovnika (1981). Međutim, omjer broja stanovnika samoga grada i njegova prstena pokazuje veliku razliku u gustoci naseljenosti i u stupnju razvijenosti (sam Zagreb ima $79 \%$ stanovnistva a okolica 21 \% stanovništva metropolitanskog područja). U nedavnoj proßlosti taj se omjer mijenjao veoma sporo, a danas je promjena ubrzana u korist okolnih naselja (rast stanovnistva i urbano prestrukturiranje). Sve do kraja razdoblja 1961-1971. rast stanovništva grada bio je veci od porasta u okolici. U razdoblju 1971-1981 trend je promijenjen; jezgra grada se prazni, a rubna naselja pune novim stanovništvom. To svjedoði u osnovi o fazi relativne decentralizacije metropolitanske regije Zagreba. Pri tome važnu ulogu imaju postojece rađijalne prometnice i satelitska sredista koja su mahom izrasla iz seoskih naselja s povoljnim geografskim položajem (Sesvete, Dugo Seio, Velika Gorica, Zapresic, Jastrebarsko, Samobor i dr). 


\section{LITERATURA}

Friganović, Mladen (1980-1981): Jos o nekim osobitostima kretanja stanovnistva opCinskih sredista i ostalih naselja SR Hrvatske 1948-1981. Radovi. Geografski odjel (zavod) PMF SveuXilista u Zagrebu, 15-16, Zagreb, s. 3-11.

Friganovic, Mladen (1982-1983): Teorijski okvir i empirijski pristup demogeografskom razvoju SR Hrvatske. Radovi, 17-18, Geografski odjel (zavod) PMF SveuciliSta u Zagrebu, Zagreb, s. 21-38.

Friganovic, Mladen (1984): Egzodusna podrux ja, (ne)razvijenost i populacijska politika u SR Hrvatskoj. Radovi, 19, Geografski odjel (zavod) PMF Sveuxilišta u Zagrebu, Zagreb, s. 29-38.

Friganovic, Mladen (1985): Demografsko-strukturne karakteristike gradskih i ostalih naselja SR Hrvatske. Radovi, 20, Gcografski odjel (zavod) PMF Sveucilišta u Zagrebu, Zagreb, s. 29-38.

Nejašmic, Ivica (1986): Prirodno kretanje stanovniłtva SR Hrvatske prema tipu naselja boravka. Rep.zav. za statistiku. Prikazi i anaiize, 59, Zagreb, s. 1-40.

Sic, Miroslav (1984): Razvoj mreže autobusnog prometa kao pokazatelj urbanizacije Zagreba. Radovi, 19, Geografski odjel (zavod) PMF Sveuxiiišta u Zagrebu, Zagreb, s. 51-58.

Šegota, Tomislav (1987): Mininalne temperature zraka u Zagrebu, Radovi, 22, Geografski odjel (zavod) PMF Sveuxilista u Zagrebu, Zagreb, s. 5-18.

Viesk, Milan (1984): Metropolitanska regija Zagreba. Radovi, 19, Geografski odjel (zavod) PMF SveuXilista u Zagrcbu, Zagreb, s. 59-66.

Vresk, Milan (1985): Urbanizacija Daimacije u uvjetima iitoraiizacije. Radovi, 20, Geografski odjel (zavod) PMF Sveucilista u Zagiebu, Zagreb, s. 31-40.

Vresk, Milan (1986): Centri rada i gravitacijska područja zaposienih u Hrvatskoj. Radovi, 21, Geografski odjel (zavod) PMF Sveuxiliłta u Zagrebu, Zagreb, s. 13-22.

Vrcsk, Milan (1987): Polarizacijski efekti urbanizacije Istre. Radovi, 22, Geografski odjel (zavod) PMF Sveuciliłta u Zagrebu, Zagreb, s. 43-53.

Vresk, Milan (1982-1983): Neka obilježja urbanizacije SR Hrvatske 1981. godine. Radovi, 17-18, Geografski odjel (zavod) PMF Sveučilista u Zagrebu, Zagreb, s. 39-54. 


\section{ABOUT DEMOGRAPHIC PROCESSES IN (NON)-URBAN AREAS OF THE SOCIALIST REPUBLIC OF CROATIA}

The degree and the main characteristics of urbanization of SR Croatia express an uniformity. Smaller areas becoming stronger demographically (immigration type) and the larger ones decreasing demographically (exodus type) are remarkable. The areas of the respective two types of the territory are in relation of 1:3, and their population in that of 1:1. It shows a different population density and different urbanization. The urban nuclei display various typologies and different degrees of rural-urban polarizations. In general, the polarization is increasing, and is increasingly pressing by discrepancy between the population density and the development (1948-1981, the share of the communal-centres population increased from $25 \%$ to $47 \%$, and the share of the population of the other, i.e. rural settlements, decreased from $75 \%$ to $53 \%$ of the population of SR Croatia). Relatively greater changes took place after the sixties, and the respective changes are very differential; regarded fron the regional aspect ZO Gospic or Lika space are of minimal urbanization, of only $22 \%$, and ZO Zagreb or Middle Croatian nuclei of even $93 \%$ ). Eight of totally $10 \mathrm{ZO}$ of SR Croatia (its community-unions or macro-regions) were of negative migration-balance within the period 1971-1981 (all of them expect ZO Zagreb and ZO Rijeka). But within the exodus areas themselves (communities and community-unions) exist the areas of expressively positive and those of negative migration-balance. The immigration areas (towns and its suburbs) are today (differently from the earlier situation) of a higher natality rate and of a higher natural-growth-rate of population than the exodus areas (rural areas). The rural areas, speaking from the demographical point of view, strongly curtailed and are no more like, let us say, an incubator of demographic processes.

Great differences in natality between urban and rural areas of SR Croatia are the fundamental negative characteristics of today. If general tiend of natural movement continues, the structure of the population of SR Croatia wil!, in its entirety, consist of greater number of the dead than the alive - as narly as at the end of the 20 th century. Today, however, the whole rural space of Croatia is that of the negative natural movement of population (greater percentage of deaths than of births).

Up to the present moment nothing has been done to prevent such an unfavourable trend. So, we must conclude that population-politics does not exist. The urbanization (deruralization) is also expressed in discordance of largeness of the central-settlements (great difference of order of largenes among republical, macro-regional, and regional centres). On the grounds of this fact and some othe- parameters, the probiem of more uniformurbanization appears, numerically and space regarded. How to solve the problem of revitalization of the villages consisting of the old-age inhabitants; the problem of derogated villages - especially on the isles and in the mountainotis districts? The socio-economic corrections and impulses should be very strong 
The present state and the projection up to the 2000 year are given below.

Year Average annual natural movement rate per 1000 inhabitants

Totally

Urban
Settlements

Mixed Settlements

2,5
1,0
$-0,2$
$-2,0$
0,5
5,7
5,1
4,2

$-1,3$

2,3
1,5
0,8
$-1,3$

2,3
1991

2000

and persistent in order to attain somewhat in this connection in near future. For, it has undoubtedly been found, there exists strong correlation between socio-economic (un)development and (de)populization. The analyses of 124 labour centres in SR Croatia show an irregular arrangement of the employment possibilities (super-concentration and desolation). How to correct such a situation knowing that polarization-concentration effects cannot be stopped for the present time? 